\title{
Envelhecimento populacional e mudanças no padrão de consumo e na estrutura produtiva brasileira
}

\author{
Rodrigo Rafael Zanon* \\ Antonio Carlos Moretto** \\ Rossana Lott Rodrigues ${ }^{* * *}$
}

Este trabalho objetiva analisar como o envelhecimento populacional pode afetar a estrutura produtiva brasileira, dadas as mudanças previstas no padrão de consumo da população no período 2005-2050. Para tanto, utilizou-se a análise insumo-produto em conjunto com informações da Pesquisa de Orçamentos Familiares (POF) de 2008-2009, da Pesquisa Nacional por Amostra de Domicílios (PNAD) de 2005 e da projeção da população do Brasil, por sexo e idade, para 1980-2050. Entre os principais resultados, observou-se que os produtos com maior consumo em favor das famílias idosas foram intermediação financeira e seguros, saúde mercantil, serviços domésticos e produtos farmacêuticos, enquanto para as famílias não idosas os destaques foram educação mercantil, vestuário, calçados e produtos do couro, transporte de passageiros e serviços de alojamento e alimentação. Quando comparada a produção necessária para satisfazer o consumo das famílias nos anos analisados, verificou-se que os setores com maior crescimento devem ser aqueles responsáveis pelos produtos com maior consumo pelas famílias idosas, com destaque para os setores produtos farmacêuticos, saúde mercantil, intermediação financeira e seguros, outros serviços, aparelho/instrumento médico-hospitalar, medida e óptico e serviços imobiliários e aluguel, ao passo que os setores com menor crescimento de sua produção devem ser educação mercantil, vestuário, calçados e produtos do couro, serviços de alojamento e alimentação, produtos do fumo, veículos automotores, peças e equipamentos. Por fim, apesar dessas diferenças observadas no crescimento dos setores, a estrutura produtiva brasileira pouco deve se alterar dadas as mudanças no consumo causadas pelo envelhecimento populacional.

Palavras-chave: Envelhecimento populacional. Consumo. Estrutura produtiva. Insumoproduto.

\footnotetext{
*Universidade Estadual de Londrina, Londrina-PR, Brasil (rodrigo_zanon@hotmail.com).

${ }^{\star *}$ Departamento de Economia da Universidade Estadual de Londrina, Londrina-PR, Brasil (acmoretto@uel.br).

*** Departamento de Economia da Universidade Estadual de Londrina, Londrina-PR (rlott@uel.br).
} 


\section{Introdução}

Analisando o comportamento da população brasileira, observa-se uma tendência ao seu envelhecimento, retratada pela diminuição da taxa de fecundidade, que passou de pouco mais de 6 filhos por mulher, até a década de 1960, para 5,30 na de 1970, 4,06 na de 1980, 2,79 na de 1990, 2,39 na de 2000 e 1,76 em 2010 (IBGE, 2008a). Este é um processo que deve se intensificar nas próximas décadas, tanto pela possível continuação da redução da taxa de fecundidade até 2013 (IBGE, 2008a), quanto pela diminuição da mortalidade dos grupos etários mais velhos, mas principalmente como resultado das quedas da fecundidade no passado.

Entre as principais consequências econômicas do envelhecimento populacional, têm-se as mudanças no mercado de trabalho (redução do crescimento ou até declínio da oferta de trabalhadores e aumento da participação de idosos no mercado de trabalho), seu impacto no crescimento econômico, as alterações nos padrões de consumo (pessoas mais velhas tendem a gastar uma parte maior de suas rendas em moradia, saúde e energia) e no comportamento de poupança dos indivíduos (como as pessoas deixam de poupar ao se aposentar, as economias com alta participação da população idosa podem experimentar alteração na taxa de poupança) (WORLD ECONOMIC AND SOCIAL SURVEY, 2007).

A mudança no padrão de consumo geral da população, uma vez que os hábitos e necessidades, a renda e outros fatores se alteram com a idade, compreende um dos resultados menos estudados deste processo, embora tenha grande importância, dado seu impacto sobre toda a estrutura produtiva do país, que deve se rearranjar para suprir essa nova demanda. Assim, o objetivo geral desse estudo é verificar o impacto do envelhecimento da população brasileira sobre a estrutura produtiva nos anos 2005, 2030 e 2050, considerando-se o padrão de consumo atual dos grupos etários. Para isto, foram utilizadas, além da Matriz InsumoProduto de 2005, a Pesquisa de Orçamentos Familiares (POF) de 2008-2009, a Pesquisa Nacional por Amostra de Domicílios (PNAD) de 2005 e a projeção da população do Brasil por sexo e idade para o período 1980-2050, todas elaboradas pelo IBGE.

O estudo está dividido em seis seções, entre as quais esta introdução. Nas duas seções seguintes são feitas duas revisões, uma teórica sobre as questões referentes ao envelhecimento populacional, e outra sobre a relação entre envelhecimento, consumo e estrutura produtiva. Posteriormente, são mostrados a metodologia empregada e o tratamento dos dados. As duas últimas seções, por sua vez, apresentam os resultados e as considerações finais do estudo.

\section{Envelhecimento populacional no Brasil}

A definição do que é um idoso depende de variados aspectos, que passam pelos culturais e vão até os biológicos, tornando difícil sua demarcação exata (CAMARANO; PASINATO, 2004). Contudo, devido a necessidades práticas, como a adoção de políticas públicas, tomase no Brasil, para determinar esse segmento populacional, o limite etário, sendo que pela 
Organização Mundial da Saúde (OMS) os idosos são as pessoas com 60 anos ou mais, para os países em desenvolvimento, e com 65 anos ou mais, para os desenvolvidos.

O envelhecimento populacional refere-se à mudança na estrutura etária da população, de forma que a participação de idosos no total da população se amplia de maneira contínua. De acordo com Moreira (2001, p. 27), "por envelhecimento populacional entende-se o crescimento da população considerada idosa em uma dimensão tal que, de forma sustentada, amplia a sua participação relativa no total da população”.

No Brasil, com o declínio da fecundidade a partir de meados da década de 1960, tem início o processo de envelhecimento da população. Aqui, como em vários outros países que apresentavam uma população muito jovem, a redução sustentada da fecundidade nas próximas décadas resultou na queda do ritmo de crescimento anual do número de nascimentos a partir de meados dos anos 1980, dando início ao processo contínuo de estreitamento da base da pirâmide etária - o envelhecimento populacional (CARVALHO; GARCIA, 2003).

Segundo Brito (2007), a transição demográfica no Brasil ocorre de maneira mais rápida e generalizada do que a verificada nos países desenvolvidos. Porém, como observa Carvalho e Garcia (2003), esses países, mesmo antes de registrarem um processo de envelhecimento populacional, já apresentavam população menos jovem, por não terem passado por período de alta fecundidade como o Brasil. Como resultados desse processo, Brito (2007) cita a diminuição do tamanho das famílias e seus novos arranjos, cada vez mais diversificados, o aumento da longevidade da população e o crescimento da população em idade ativa nas próximas décadas.

De acordo com o Banco Mundial (2011), o padrão demográfico brasileiro apresenta cinco características principais: seu processo de transição demográfica se encontra muito mais avançado se comparado aos outros países da América Latina; a taxa de fecundidade tem baixado muito mais rapidamente do que foi observado nos países europeus (no Brasil diminuiu de 3 para 2 filhos por mulher em 19 anos, enquanto na Europa a mesma queda levou 60 anos em média); a redução da mortalidade não tem sido tão rápida e profunda quanto a da fecundidade; a estrutura etária da população tem mudado rapidamente; e a estrutura etária atual é muito favorável dada a concentração da população em idade ativa.

Segundo o último Censo Demográfico (IBGE, 2011), a população brasileira alcançava 190,8 milhões em 2010, dos quais 42,03\% pertenciam ao grupo etário entre 0 e 24 anos de idade, $47,18 \%$ ao de 25 a 59 anos e $10,79 \%$ ao de 60 anos ou mais. Considerandose que em 2000 os mesmos grupos etários correspondiam a 49,67\%, 41,76\% e 8,56\%, respectivamente, observa-se uma gradual mudança na composição destes no período 2000-2010, com diminuição do segmento jovem e aumento dos grupos de adultos e idosos.

Segundo Guimarães (2006), além de seu tamanho crescente, a população idosa possui outras características que levam a novas oportunidades de negócios ainda não supridas. Entre estas características é possível observar que a renda do idoso tem caráter mais permanente do que a de outros grupos etários, seja pela sua composição (na maior parte aposentadorias e pensões), seja pela poupança efetuada durante sua vida. 
O elevado número de idosos chefes de família mostra que eles assumem, cada vez mais, o papel de colaborar com a renda familiar, de forma que as transferências entre gerações tornam-se bidirecionais. Isto porque diversos eventos, como as crises econômicas ocorridas recentemente, o desemprego (principalmente entre os jovens) e a instabilidade das uniões, têm tornado muitos filhos adultos dependentes de seus pais (GUIMARÃES, 2006).

A menor dependência dos idosos em relação às suas famílias pode ser explicada, também, pelo fato de que, no Brasil, assim como nos países desenvolvidos, as transferências públicas para o grupo etário idoso correspondem à maior parte das suas necessidades de consumo, enquanto o consumo dos grupos mais jovens fica a cargo, principalmente, das transferências privadas (transferências familiares), fato que surpreende em razão da estrutura ainda jovem da população (TURRA et al., 2011).

\section{Envelhecimento populacional, consumo e estrutura produtiva}

Muitos estudos têm sido feitos com o objetivo de avaliar como a transição demográfica deve afetar o crescimento econômico em diversos países. Isto porque, durante esse processo, há um período, denominado de janela demográfica, no qual a população dependente se reduz, o que significa mais recursos disponíveis para serem investidos na economia, além do fato de que o aumento da longevidade, ao afetar o comportamento de poupança da população economicamente ativa, deve criar efeito positivo no nível de renda (QUEIROZ; TURRA, 2010).

Ademais, é preciso lembrar que o envelhecimento populacional deve trazer mudanças na economia, uma vez que os níveis de consumo e renda se modificam com a idade, fato estilizado nos modelos de ciclo de vida econômico. No Brasil, o consumo privado e a renda do trabalho apresentam uma relação clássica de déficit (consumo maior do que a renda) no primeiro (pré-trabalho) e último (pós-trabalho) estágios, e de superávit (renda maior que o consumo) no estágio intermediário (trabalho). Dessa forma, o consumo desses grupos que se encontram no estágio deficitário é financiado por transferências públicas e privadas (BANCO MUNDIAL, 2011).

Entre os aspectos determinantes do consumo de um indivíduo, ou do padrão de consumo de uma população, podem-se incluir suas preferências, sua renda, o preço dos bens e serviços, a taxa de juros, a renda esperada e sua riqueza (DORNBUSCH; FISCHER, 1991). Todos estes fatores são, de certa forma, influenciados pela idade do consumidor: os indivíduos mais velhos, seja por gosto ou necessidade, não consomem as mesmas coisas de quando eram jovens; o preço dos produtos destinados aos idosos tende a ser mais caro e com inflação mais elevada; a taxa de juros, em muitos casos, é mais atrativa para aposentados; a renda para grande parte dos idosos tem uma constância maior dada a aposentadoria; e a riqueza também tende a ser maior para o grupo idoso (NERI et al., 2004; CAMARANO; PASINATO, 2004). Por estas e outras razões, a mudança na estrutura etária de um país deve trazer como consequência a modificação no padrão de consumo de sua população. 
Hagemann e Nicoletti (1989) afirmam que a distribuição etária da população tem efeito sobre a importância relativa dos diferentes produtos na estrutura do consumo privado, dado que a idade é um importante determinante das preferências. Assim, em geral, as categorias do consumo que mais declinariam em uma sociedade em processo de envelhecimento seriam educação, transporte, recreação e bens duráveis, além de serviços domésticos, enquanto alimentação, a maioria dos serviços e, particularmente, cuidados médicos deveriam aumentar.

Analisando o comportamento e estilo de vida da população idosa brasileira e seu poder de consumo, Ballstaedt (2007) afirma que o envelhecimento populacional traz novo nicho de mercado consumidor, com diferentes valores, comportamentos e necessidades específicas, nicho este que ainda não é aproveitado, visto que a maior parte dos produtos vendidos para idosos está relacionada à saúde, enquanto ainda há muitos outros a serem explorados, como cosméticos, turismo, lazer e educação, por exemplo.

De acordo com o World Economic and Social Survey (2007), ao se observar o padrão de consumo da população idosa nos países desenvolvidos, é possível prever que a demanda por saúde aumentará com o envelhecimento populacional e que os gastos com moradia e energia crescerão como resultado do maior tempo despendido em casa por esta população. Por outro lado, gastos com entretenimento e transporte devem cair, enquanto a participação do consumo de bens básicos como alimentos e vestuário deve permanecer constante.

A renda, entretanto, deve continuar sendo a principal determinante da estrutura e do nível de demanda da economia. Portanto, ao se analisar a influência da mudança demográfica no padrão de consumo, é necessário considerar a relação entre idade e renda. Se a renda muda com a idade e uma idade mais avançada implica uma menor renda em algumas circunstâncias, então, uma população idosa crescente irá afetar a estrutura de demanda não apenas pela mudança de preferências e necessidades, mas, também, pelas alterações na renda trazidas pela idade. Uma renda menor para um crescente número de idosos levará a uma redução no nível de consumo e este se deslocará para os bens de necessidade básica. Por isso, ao se projetar a estrutura da demanda no futuro, é também preciso levar em conta possíveis mudanças no poder de compra da população idosa (WORLD ECONOMIC AND SOCIAL SURVEY, 2007).

Neri et al. (2004) verificaram as principais diferenças nas proporções dos gastos das famílias com pelo menos 50\% de idosos (os autores denominam idosos aqueles com 65 anos ou mais) em relação às proporções dos gastos das famílias em geral no Brasil. Entre os itens que apresentaram maior proporção de gastos nas famílias com idosos, destacaram-se despesas com saúde e cuidados pessoais, alimentação, despesas diversas e com habitação. Por outro lado, os itens com menor proporção de gastos nas famílias com idosos em relação ao total de famílias corresponderam a transportes, vestuário, educação, leitura e recreação.

Almeida (2002), partindo da hipótese de que a renda do idoso tem papel expressivo no contexto familiar, principalmente entre as famílias com renda mais baixa, analisou o consumo das famílias com idosos e sem idosos no Brasil por meio de um modelo lógite, de forma a verificar a probabilidade de estas famílias adquirirem determinados bens e serviços. A partir 
de dados da POF de 1995-1996 sobre dispêndios não alimentares (exceto alimentação fora do domicílio), o autor observou que o resultado mais significativo foi o aumento dos gastos com serviços de saúde e produtos farmacêuticos nas famílias com idosos, além de despesas pessoais, roupas, lazer, jogos e apostas. Outro resultado que pode ser ressaltado refere-se à importância da renda dos idosos dentro da estrutura familiar, os quais, dada a sua renda estável, elevam o poder de compra de toda a família.

Como a estrutura produtiva de um país está intrinsecamente ligada à demanda de consumo de sua população, ela será fortemente influenciada por uma mudança nesta demanda, tanto diretamente, pela alteração no consumo final, quanto indiretamente para responder às necessidades das indústrias produtoras, o consumo intermediário.

Dewhurst (2006) e Albuquerque e Lopes (2009) buscaram quantificar os impactos setoriais da evolução dos padrões de consumo associados ao envelhecimento, na Escócia e em Portugal, respectivamente. Para isto, os autores desagregaram a coluna de consumo das famílias da matriz insumo-produto destes países em diferentes grupos de idade - idosos e não idosos -, com base em pesquisas de gastos familiares. Eles também utilizaram projeções demográficas para prever possíveis mudanças na importância relativa dos setores produtivos, ou seja, quais terão oportunidades de expansão e quais devem contrair-se.

Os resultados das projeções para a Escócia foram que a demanda se expandirá nos setores utilidades, serviço social, saúde e seguros, enquanto retrairá nos setores hotéis, restaurantes e bares e aluguéis de imóveis (DEWHURST, 2006). Para Portugal, os autores verificaram que os setores com maior crescimento serão os de instrumentos médicos e de precisão e relógios, produtos químicos, construção civil e energia, enquanto os setores com decréscimo serão os serviços públicos, educação, materiais de escritório e computadores, rádio, televisão e equipamentos de comunicação (ALBUQUERQUE; LOPES, 2009).

Lührmann (2005) analisou o efeito futuro do envelhecimento populacional sobre a demanda de bens e serviços, entre 2000 e 2040, para a Alemanha. Por meio da estimação da demanda das famílias, de acordo com a idade, para um grupo de oito bens, foram projetados quatro cenários com o objetivo de distinguir o efeito direto de uma mudança na estrutura etária, e as mudanças no nível e na distribuição do poder de compra diante da alteração da composição familiar. Os resultados apontaram significativo aumento na participação dos gastos em saúde e lazer e um declínio em alimentação e energia. O efeito direto da mudança na estrutura etária foi significativo para a demanda agregada. Já a mudança na composição das famílias não afetou a demanda substancialmente.

DellaVigna e Pollet (2007) estudaram como a alteração na demanda ocasionada pela mudança demográfica, nos Estados Unidos, pode modificar a lucratividade das empresas, influenciando, por fim, o mercado de ações. Para isso, os autores traçaram a evolução do consumo da população americana, por idade, utilizando dados de 1935-36, 1960-61, 1972-73 e 1983-84, chegando às seguintes conclusões: o consumo de cada bem depende significativamente da idade do chefe de família; chefes de família mais jovens consomem, por exemplo, mais bens para o cuidado de crianças e brinquedos, os na meia idade consomem 
mais seguros de vida e cigarros e os mais velhos gastam mais com viagens e casas de repouso; e o padrão de consumo de móveis para a faixa-etária de 25 a 35 anos é praticamente estável ao longo do tempo.

O conjunto dos estudos aqui levantados mostra que a idade exerce grande influência na determinação do consumo de um indivíduo e, consequentemente, de sua família e, portanto, a mudança na estrutura etária traz impactos sobre o padrão de consumo de toda a sociedade, afetando, por fim, a estrutura produtiva do país.

\section{Metodologia}

\section{Fonte e tratamento dos dados}

Para analisar os impactos na estrutura produtiva de uma mudança na estrutura etária e sua consequente alteração no consumo, foram utilizadas a Matriz Insumo-Produto (MIP) do Brasil para 2005 (IBGE, 2008b), a Pesquisa de Orçamentos Familiares (POF) de 20082009 (IBGE, 2009b), a projeção da população do Brasil por sexo e idade para o período 1980-2050 (IBGE, 2008a) e a Pesquisa Nacional por Amostra de Domicílios (PNAD) de 2005 (IBGE, 2005). A POF e a PNAD são empregadas para desagregar os vetores consumo das famílias e salários da MIP, respectivamente, entre a população idosa e a não idosa. Assim, com a utilização do instrumental insumo-produto, podem ser verificadas as mudanças entre a estrutura produtiva atual (2005) e a futura (2030 e 2050), neste caso aplicando a projeção da população para se obter o consumo dos grupos etários de então. Tal período foi escolhido por ser 2005 o ano da última matriz brasileira divulgada pelo IBGE, 2050 por ser o último ano com projeção para a população disponível e 2030 por estar, aproximadamente, entre esses outros dois anos.

A POF de 2008-2009 foi utilizada por ser a última disponível. A unidade de consumo (UC), ou família, como também pode ser chamada, é a unidade básica de investigação e análise dos orçamentos na POF, podendo ser formada por um único morador ou conjunto de moradores que compartilham da mesma fonte de alimentação (IBGE, 2010). Estas UCS foram desagregadas em unidades de consumo idosa e não idosa. Assim, a UC foi considerada idosa quando $50 \%$ ou mais de seus membros tinham 60 anos ou mais, e não idosa no caso contrário.

Os dados de despesa com os diferentes tipos de bens e serviços têm na POF periodicidade variada, como 7, 30 e 90 dias e 12 meses. Portanto, para obter as despesas, foi utilizada a variável valor da despesa anualizado e expandido, que permite comparar os gastos com diferentes periodicidades, ao torná-los anuais, deflacioná-los e expandi-los pelo fator de expansão da amostra.

Na POF de 2008-2009, encontram-se milhares de itens de despesas diferentes, enquanto na MIP observam-se 110 produtos e 55 setores de atividades. Dados os propósitos da pesquisa e a necessidade de compatibilização entre o número de atividades da POF e da 
MIP, estes 110 produtos da matriz foram agregados em 51 produtos, para só então serem relacionados às despesas da POF. Um problema encontrado refere-se ao comércio, que apresenta consumo das famílias na matriz, mas não está contabilizado na POF. Para este setor, foi utilizada como proxy a média da atividade de serviços, considerando que esta atividade apresenta características mais próximas ao comércio. Além da agregação prévia de produtos da matriz, explicada anteriormente, foi necessária, também, a agregação dos setores de atividades da MIP, os quais passaram de 55 originalmente, para 38, dado que na POF o agrupamento de produtos em setores resultou em 38 setores de atividades. Na PNAD também foi feita uma compatibilização entre os seus grupamentos de atividades e os 38 setores da matriz insumo-produto aqui utilizada. ${ }^{1}$

Com as despesas da POF compatibilizadas aos produtos da matriz e com a desagregação destas entre famílias idosas e não idosas, foi encontrada a proporção do consumo destes dois grupos etários, a qual foi aplicada de acordo com cada produto no vetor consumo das famílias da Tabela 3 de oferta e demanda da produção a preço básico da MIP.²

Posteriormente, a projeção da população por faixa etária para 2030 e 2050 (IBGE, 2008a) foi aplicada aos vetores previamente encontrados de consumo dos idosos e não idosos, com o intuito de se obterem novos arranjos que permitiram avaliar o impacto do envelhecimento na configuração da estrutura produtiva brasileira. Considerou-se que a proporção de domicílios idosos e não idosos de 2005 correspondia à proporção de idosos e não idosos na população brasileira neste mesmo ano, mantendo-se a mesma regra para os períodos seguintes, ou seja, manteve-se a composição domiciliar constante. Admite-se, para o propósito do estudo, que a composição dos gastos de ambos os grupos etários seja constante ao longo do tempo, ou seja, que as famílias não mudem a divisão de seus orçamentos, mantendo os mesmos hábitos de consumo. Também é importante lembrar que, para o cálculo das projeções de consumo, consideram-se apenas o crescimento populacional e a respectiva estrutura etária da população.

Cabe salientar que a manutenção da composição domiciliar e da estrutura etária da população pode afetar, de alguma forma, os resultados. No entanto, no caso da primeira, Lührmann (2005) argumenta que os resultados não são afetados substancialmente ao longo do período. No segundo caso, a alteração na estrutura etária pode mudar os resultados na medida em que o consumo da família mudaria como um todo. Como o que se espera é que esta mudança resulte em famílias com mais idosos, o aumento do consumo dos produtos por elas demandados seria maior. Assim, embora os resultados não meçam exatamente o comportamento do consumo das famílias, eles fornecem uma boa orientação deste ao longo dos anos em foco.

Na PNAD, a divisão entre a população idosa e não idosa foi feita por indivíduo, sendo considerados idosos aqueles com 60 anos ou mais e os não idosos os com até 59 anos.

\footnotetext{
${ }_{1}^{1}$ Para mais detalhes sobre a agregação de produtos e setores, ver Zanon (2012).

${ }^{2}$ A MIP de 2005, divulgada pelo IBGE (2008b), é composta por um conjunto de nove tabelas. Portanto, a Tabela 3 mencionada acima refere-se à Tabela 3 do conjunto das tabelas da MIP.
} 
O salário desses indivíduos foi retirado da MIP, que corresponde ao valor recebido livre de contribuições sociais efetivas, como previdência oficial/FGTS e previdência privada.

Como a variável de interesse nesta pesquisa foi o salário, excluíram-se os índios, por apresentarem pouca representatividade no que diz respeito aos objetivos da pesquisa, as pessoas não economicamente ativas (PNEA), as pessoas que exercem alguma atividade, contudo sem remunerações monetárias e que se encontraram na condição de desocupados, os aposentados e pensionistas.

Com estes dados da PNAD, foram obtidas as proporções do total de salários e do número de ocupados para os dois grupos etários e para cada setor, sendo feita a aplicação destas proporções, respectivamente, aos vetores linha de salários e do número de ocupados da Tabela 2 de usos de bens e serviços a preço de consumidor da MIP. ${ }^{3}$

\section{Modelo insumo-produto}

Leontief foi o responsável, em 1936, pela primeira aplicação empírica do modelo de insumo-produto. Neste, as variáveis fundamentais são os produtos dos inúmeros setores de uma economia, os quais são constituídos pela soma de suas vendas aos outros setores e pela demanda final. Quando a produção e as vendas de cada setor se igualam, a economia está em equilíbrio. As compras de um setor são determinadas pela produção de todos os outros setores. Dessa forma, a análise de insumo-produto permite, além de identificar, medir a interdependência da estrutura econômica (RICHARDSON, 1978).

Para se derivar o sistema aberto de Leontief, com a demanda final exógena a ele, precisase obter os coeficientes técnicos, que indicam a quantidade de insumo do setor $i$ necessária para a produção de uma unidade de produto final do setor $j$ (MILLER; BLAIR, 2009). Assim:

$$
a_{i j}=\frac{z_{i j}}{x_{j}}
$$

O coeficiente $a_{i j}$ descreve, portanto, uma relação fixa entre os insumos utilizados $\left(z_{i j}\right)$ e o produto de cada setor $\left(x_{j}\right)$.

Por conseguinte, o sistema aberto de Leontief pode ser encontrado da seguinte maneira:

$$
x_{i}=\sum_{j=1}^{n} a_{i j} x_{j}+y_{i}
$$

em que, $y_{i}$ é a demanda final por produtos do setor $i$.

Reescrevendo a equação (2) em forma matricial, tem-se:

$$
\mathrm{x}=\mathrm{Ax}+\mathrm{y}
$$

em que x é o vetor dos produtos totais de cada setor, de ordem $(n \times 1)$; A corresponde à matriz de coeficientes diretos de insumo, de ordem $(n \times n)$; e y refere-se ao vetor da demanda final total por setor $(C+I+G+E)$, de ordem $(n \times 1)$. A partir da equação (3), pode-se obter o vetor de produção total necessário para satisfazer a demanda final:

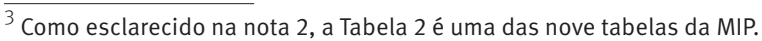




$$
\mathrm{x}=(\mathrm{I}-\mathrm{A})^{-1} \mathrm{y}
$$

em que $(\mathrm{I}-\mathrm{A})^{-1}=\mathrm{B}$ é a matriz conhecida como inversa de Leontief ou matriz de coeficientes diretos e indiretos, de ordem $(n \times n)$. Nela, cada elemento corresponde à produção total do setor $i$ necessária para produzir uma unidade de demanda final do setor j (GUILHOTO, 2006). Dessa forma, ao aumentar a demanda de um setor, elevar-se-á a produção necessária dos setores que the fornecem insumos, os quais também necessitarão de mais insumos, levando a um efeito indireto de encadeamento.

Podem-se endogeneizar o consumo e a renda das famílias de forma a calcular também o efeito induzido, o qual pode ser explicado da seguinte maneira: as famílias obtêm sua renda (pelo menos em parte) pelo pagamento ao seu trabalho no processo produtivo e, como consumidoras, também gastam sua renda de acordo com um padrão definido. Assim, um aumento na quantidade de trabalho demandada por um setor, dada a necessidade de acréscimo de sua produção, eleva a renda total recebida pelas famílias, o que aumenta também seus gastos, gerando então novo incremento na demanda, novas contratações e assim por diante (MILLER; BLAIR, 2009).

Este sistema, denominado como fechado às famílias, requer que os vetores de coeficientes do consumo das famílias e da renda sejam adicionados à matriz A de coeficientes diretos de insumo que passa a ser chamada de $\overline{\mathrm{A}}$, de ordem $(n+1) \times(n+1)$. Têm-se, também, novos vetores de produção total, $\overline{\mathbf{x}}$, de ordem $(n+1) \times(n+1)$, e de demanda final, $\overline{\mathrm{y}}$, de ordem $(n+1) \times(n+1)$.

$\mathrm{O}$ sistema de Leontief passa a ser representado como:

$$
\overline{\mathrm{x}}=(\mathrm{I}-\overline{\mathrm{A}})^{-1} \overline{\mathrm{y}}
$$

em que $(\mathrm{I}-\overline{\mathrm{A}})^{-1}=\overline{\mathrm{B}}$ representa a matriz dos efeitos diretos, indiretos e também induzidos, de ordem $(n+1) \times(n+1)$. Assim, quando o impacto de um acréscimo no consumo, dado um aumento na renda, é considerado no modelo, revela-se um produto maior dos setores em relação ao caso em que ambos são ignorados.

\section{Projeção do produto por setor}

Com o objetivo de comparar o produto de cada setor para os três períodos analisados (2005, 2030 e 2050), utilizaram-se a inversa de Leontief endogeneizada (modelo fechado às famílias), o consumo de 2005 e suas projeções para 2030 e 2050.

Assim, como visto na equação (5), ao se multiplicar a inversa $(\mathrm{I}-\overline{\mathrm{A}})^{-1}$ pelo vetor coluna $\overline{\mathrm{y}}$ de demanda final (neste caso o consumo das famílias), tem-se como resultado o vetor $\overline{\mathbf{x}}$, a produção total necessária para satisfazer essa demanda. Com a aplicação do consumo para cada ano pesquisado, obteve-se o produto dos mesmos, por setor.

Este produto corresponde ao necessário para satisfazer a demanda criada, ou seja, precisa cobrir os efeitos diretos (suprir a demanda final), os efeitos indiretos (suprir as necessidades geradas nos outros setores) e os efeitos induzidos (produto adicional necessário para suprir os novos gastos dos consumidores gerados pelo aumento na sua renda) (MILLER; BLAIR, 2009). 
Esta projeção do produto, entretanto, está relacionada apenas ao crescimento da população, excluindo-se o crescimento econômico devido a outros fatores como o avanço tecnológico.

\section{Resultados e discussão}

A divisão entre idosos e não idosos por meio da POF de 2008-2009 resultou em uma proporção de 10,58\% de idosos, ou seja, pessoas com 60 anos ou mais, e 89,42\% de não idosos, pessoas com até 59 anos. Por sua vez, a divisão entre as unidades de consumo (famílias) idosas e não idosas obteve diferentes proporções: 15,26\% delas foram consideradas idosas (UC com pelo menos $50 \%$ de idosos) e $84,74 \%$ não idosas (UC com menos de $50 \%$ de idosos).

Segundo a matriz insumo-produto de 2005 (IBGE, 2008b), o consumo das famílias foi de 1.086.708 milhões de reais, sendo que, deste total, 923.441 milhões de reais foram consumidos pelas famílias não idosas (84,98\%) e 163.266 milhões de reais pelas famílias idosas (15,02\%).

Partindo dessas considerações, pode-se verificar na Tabela 1 a participação de cada produto no consumo das famílias idosas e não idosas. As principais diferenças observadas foram: o produto intermediação financeira e seguros (40), apesar de estar entre os mais consumidos para ambas as famílias, respondeu por uma parcela muito maior no orçamento das famílias idosas (13,09\%) do que no das não idosas (7,69\%); outro produto que merece destaque é saúde mercantil (46), que obteve participação de 6,94\% no consumo total das famílias idosas, ao passo que nas não idosas correspondeu a 4,43\%; alguns produtos como serviços domésticos (48) e produtos farmacêuticos (23), por sua vez, tiveram maior destaque para as famílias idosas do que para as não idosas; por outro lado, educação mercantil (45), vestuário, calçados e produtos do couro (17), serviços de alojamento e alimentação (43), transporte de passageiros (47) e serviços prestados às famílias e associativos (47) se destacaram entre os produtos que têm maior participação no consumo total das famílias não idosas.

Interessante, também, notar que a soma dos dez produtos mais consumidos correspondeu a $66,88 \%$ para as famílias idosas e $60,50 \%$ para as não idosas, mostrando uma concentração ligeiramente maior dos gastos nas primeiras. Contudo, apesar das diferenças observadas, os serviços imobiliários e aluguel inclusive imputado (41) constituíram o produto com maior participação no orçamento tanto das UCs idosas quanto das não idosas. Estes serviços, embora incluam os aluguéis imputados, ou seja, os aluguéis para quem tem moradia própria, também consideram os gastos das famílias com aluguéis (quando estas não têm moradia própria), serviços de corretagem, administração de imóveis, etc.

Cabe esclarecer que, nas Tabelas 1 e 3, os produtos educação pública (49), saúde pública (50) e serviço público e seguridade social (51) aparecem com valor zero, pois não são pagos diretamente pelas famílias, sendo, portanto, tidos como serviços prestados pelo Estado. 
TABELA 1

Valor e participação dos produtos no consumo total das famílias, por grupos etários Brasil - 2005

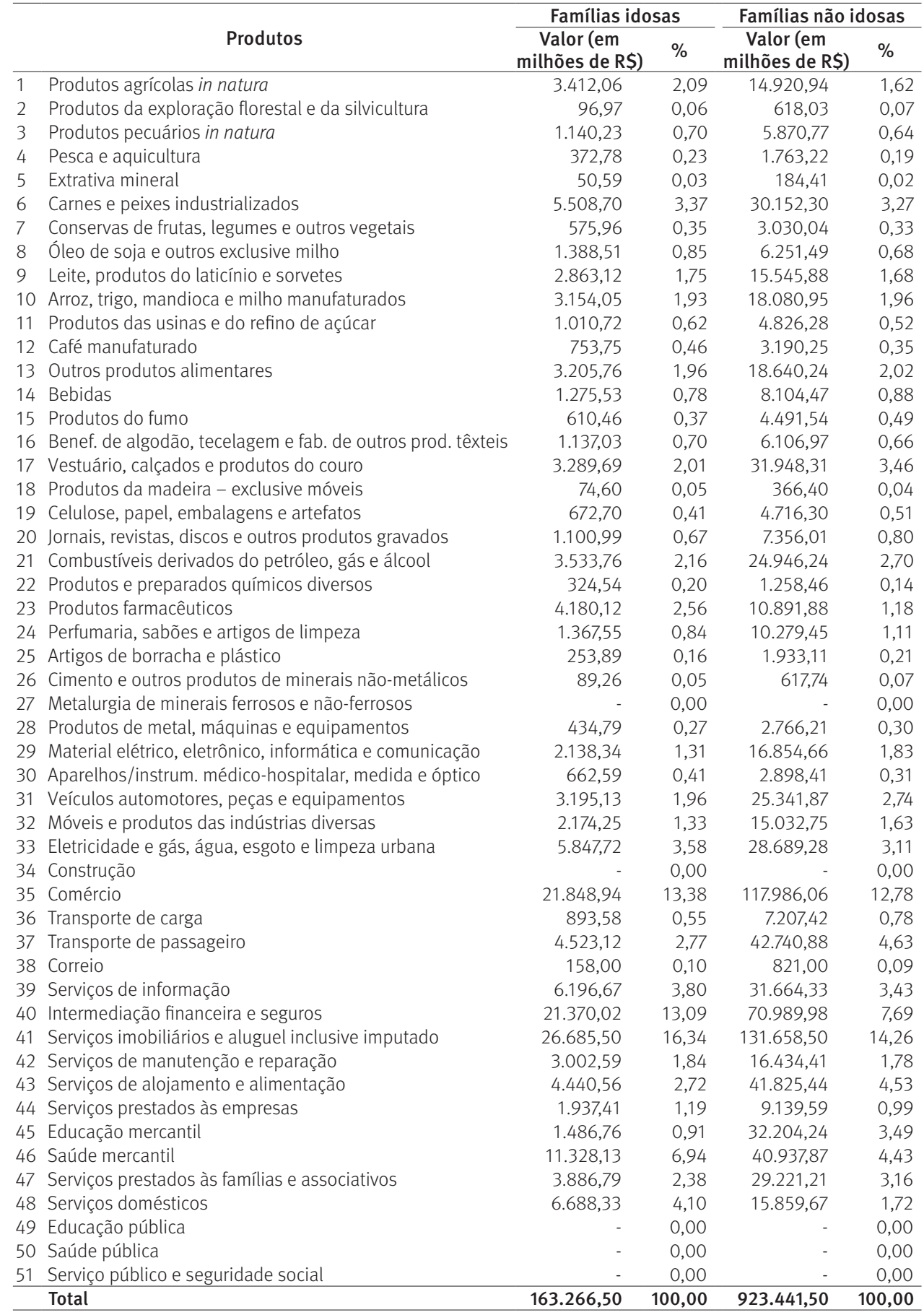

Fonte: IBGE. Matriz de insumo-produto Brasil 2005; Pesquisa de Orçamentos Familiares 2008-2009. 
Para observar as alterações no consumo causadas pelas mudanças na estrutura etária, foram comparadas as proporções dos grupos de idade entre 2005 e as previsões de 2030 e 2050, resumidas na Tabela 2.

Verificou-se que a população total deve aumentar até 2030, porém, em 2050, esta deverá apresentar decréscimo, o qual será causado pela diminuição do grupo de não idosos (até 60 anos), que representará pouco mais de $70 \%$ da população total, enquanto o de idosos (60 anos ou mais) continuará aumentando, chegando a quase 30\% em 2050.

TABELA 2

Distribuição da população de idosos e não idosos

Brasil - 2005-2050

\begin{tabular}{|c|c|c|c|c|c|c|}
\hline \multirow{2}{*}{$\begin{array}{l}\text { Grupos } \\
\text { etários }\end{array}$} & \multicolumn{2}{|c|}{2005} & \multicolumn{2}{|c|}{2030} & \multicolumn{2}{|c|}{2050} \\
\hline & População & $\%$ & População & $\%$ & População & $\%$ \\
\hline Idosos & 16.943 .119 & 9,21 & 40.472 .804 & 18,70 & 64.050 .980 & 29,75 \\
\hline Não Idosos & 166.937 .775 & 90,79 & 175.937 .226 & 81,30 & 151.236 .483 & 70,25 \\
\hline Total & 183.880 .894 & 100,00 & 216.410 .030 & 100,00 & 215.287 .463 & 100,00 \\
\hline
\end{tabular}

Fonte: IBGE. Pesquisa Nacional por Amostra de Domicílios 2005; Projeção da população do Brasil por sexo e idade para o período 1980-2050: revisão 2008 .

Ao se projetarem estas mudanças na estrutura etária, podem ser verificadas as diferenças resultantes da participação de cada produto no consumo entre 2005 e 2050 (Tabela 3). Tem-se, então, que os produtos que mais devem ampliar sua participação no orçamento das famílias em geral são aqueles mesmos que obtiveram maior participação relativa do consumo para as famílias idosas, enquanto os produtos que mais devem perder participação no orçamento familiar são, basicamente, aqueles referentes ao consumo das famílias não idosas.

As diferenças encontradas no padrão de consumo dos grupos etários estão de acordo com Hagemann e Nicoletti (1989) quanto à importância da idade na determinação do consumo das famílias. Sobre a composição do consumo desses grupos etários, os resultados condizem com os encontrados por Neri et al. (2004) e Almeida (2002), também para o Brasil. Além disso, pode-se verificar que as mudanças no consumo geral da população, de 2005 a 2050, são semelhantes às observações do World Economic and Social Survey (2007) para os países desenvolvidos, que apontou o crescimento dos gastos com saúde, moradia e energia e decréscimo dos dispêndios com entretenimento e transportes.

Com a projeção do consumo das famílias, pela taxa de crescimento da população apenas, foi possível estimar a produção necessária para supri-lo. Esta produção engloba não apenas aquela para abastecer a demanda final das famílias, mas também a demanda gerada no processo produtivo pelos outros setores e pelo efeito renda. 0 total deste produto passou de, aproximadamente, 2,932 trilhões de reais em 2005, para 3,690 e 3,947 trilhões de reais em 2030 e 2050 , respectivamente. 
TABELA 3

Participação no total do consumo das famílias, segundo produtos Brasil - 2005-2050

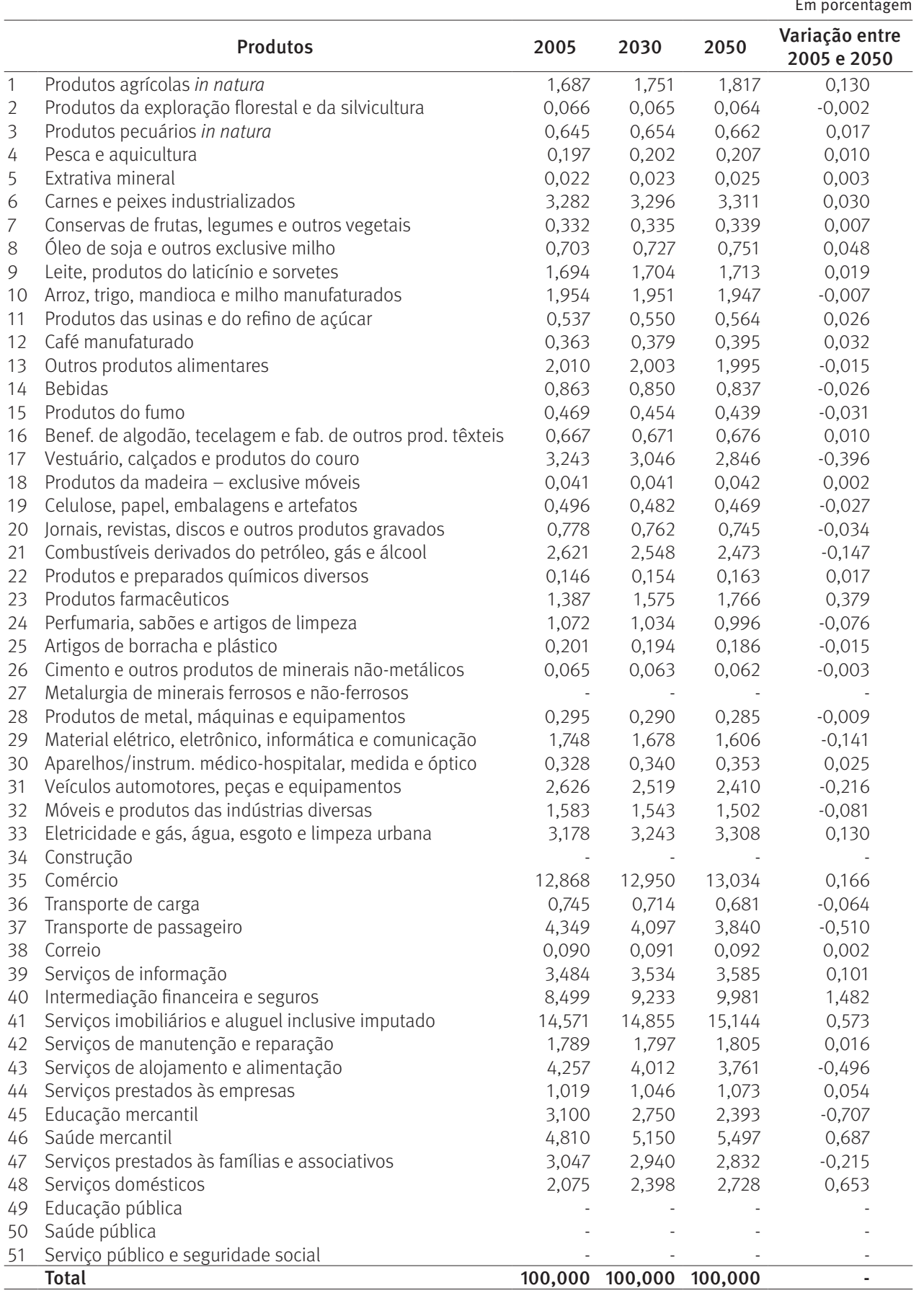

Fonte: IBGE. Projeção da população do Brasil por sexo e idade para o período 1980-2050: revisão 2008; Matriz de insumo-produto Brasil 2005; Pesquisa de Orçamentos Familiares 2008-2009. 
A Tabela 4 permite observar como se comportou, em âmbito geral, a estrutura produtiva da economia quanto à produção destinada ao consumo das famílias na comparação dos anos 2005, 2030 e 2050. Nela está listada a produção estimada para todos os setores. Importante notar que, como esta produção não visa apenas a demanda final, entre os setores com maior produção incluem-se não somente os que apresentam maior consumo das famílias. Entre os setores com maior importância na produção ao longo do período, podem ser citados transporte, armazenagem e correio (26), combustíveis derivados do petróleo, gás e álcool (11), agricultura, silvicultura e exploração florestal (1) e serviços prestados às empresas (32).

Em todo o período analisado, não foram observadas trocas de posição entre os setores com maior produção, embora estes tenham apresentado diferentes taxas de crescimento. Além disso, verificou-se crescimento bem maior do produto entre 2005 e 2030 (mais de 750 bilhões de reais no total) do que entre 2030 e 2050 (pouco mais de 250 bilhões de reais no total). Isto pode ser explicado, principalmente, pela inflexão prevista na taxa de crescimento da população em 2040 (IBGE, 2008a), quando deverá iniciar um declínio, embora também é preciso observar que o segundo intervalo de tempo apresenta cinco anos a menos do que o primeiro.

Utilizando-se índices, nos quais a produção de 2005 foi considerada 100, têm-se, ainda na Tabela 4, os índices de crescimento do produto entre 2005 e 2050 para todos os setores. Constatou-se que os setores com maior destaque foram, em sua maioria, aqueles que produzem os produtos mais consumidos pelo grupo etário idoso, como produtos farmacêuticos (13), saúde mercantil (34), intermediação financeira e seguros (28), outros serviços (35), serviços imobiliários e aluguel (29) e serviços de informação (27).

Enquanto isso, entre os outros setores com maiores índices, apesar de apresentarem elevado crescimento, apenas os de aparelho/instrumento médico-hospitalar, medida e óptico (20) e serviços prestados às empresas (32) apresentaram nível de produção razoável, sendo pouco representativa, para satisfazer o consumo das famílias, a produção dos setores educação pública (36) e saúde pública (37).

Entre os dez setores com menores índices, oito são responsáveis pela produção de produtos consumidos, em sua maioria, por famílias não idosas: perfumaria, higiene e limpeza (14); material elétrico, eletrônico, informática e comunicação (19); transporte, armazenagem e correio (26); veículos automotores, peças e equipamentos (21); produtos do fumo (5); serv. de alojamento e alimentação (31); vestuário, calçados e produtos do couro (7); e educação mercantil (33), sendo que este último passa a apresentar decréscimo da produção entre 2030 e 2050 (de 54,8 para 53,4 bilhões de reais).

Já os setores metalurgia de metais ferrosos e não-ferrosos (17) e móveis e produtos das indústrias diversas (22) revelaram baixos índices, principalmente por serem fornecedores de insumos para a produção nos outros setores que também apresentaram baixo crescimento. 


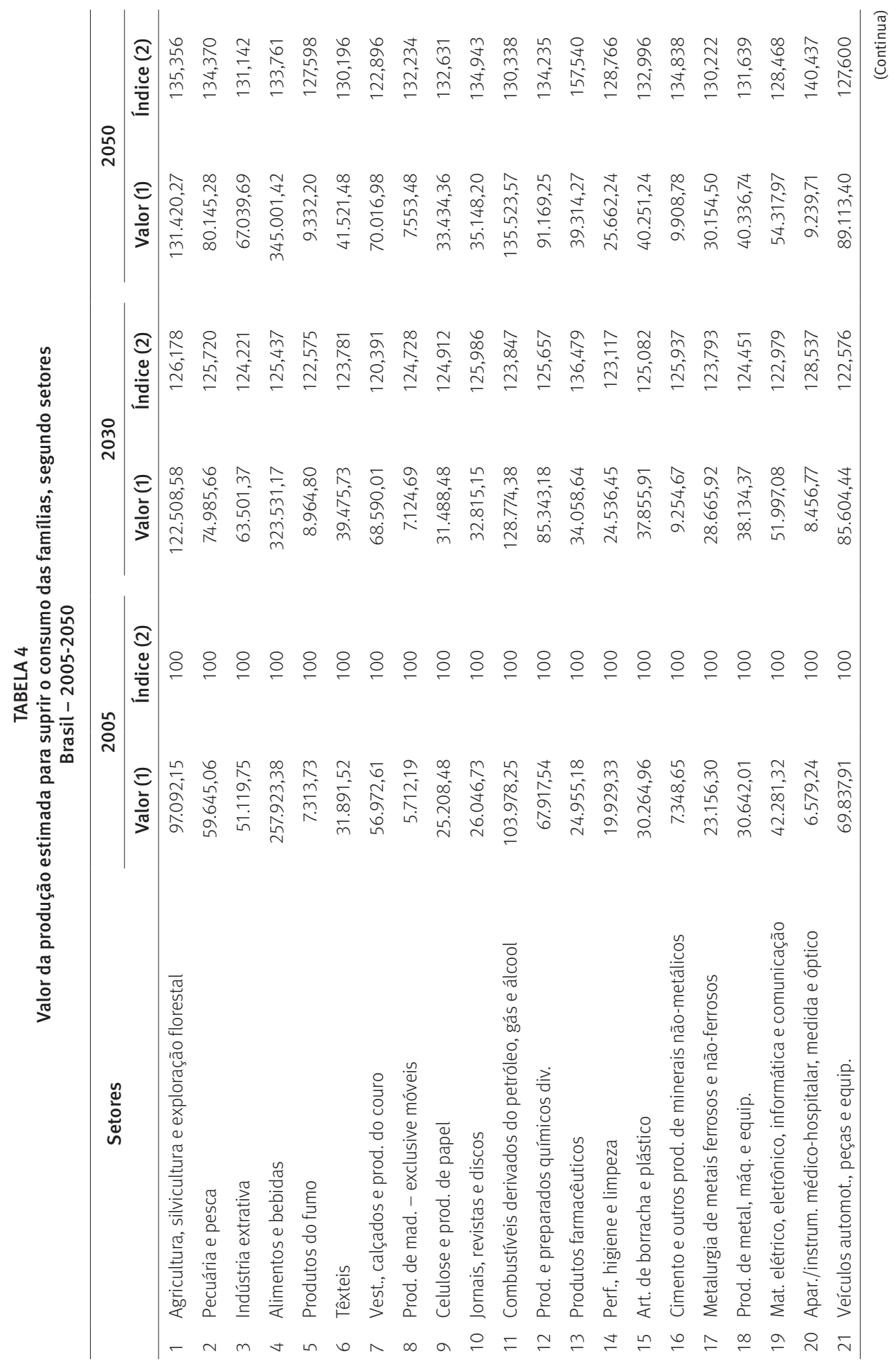




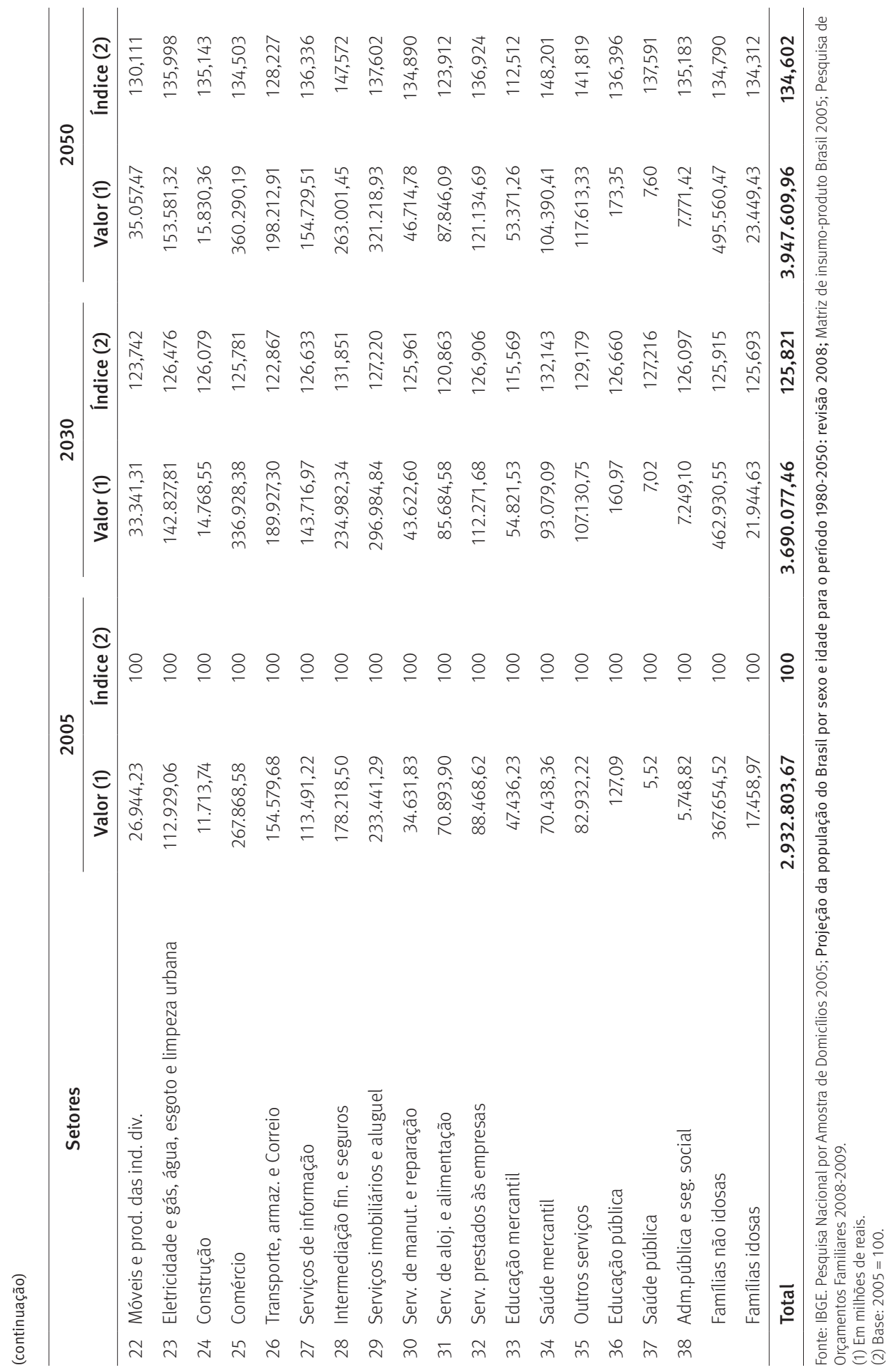


Pela Figura 1 pode-se visualizar a evolução da estrutura produtiva da economia quanto à produção destinada ao consumo das famílias entre os extremos do período analisado. Os números dos setores na Figura 1 correspondem àqueles constantes na Tabela 4. A linha contínua representa a produção dos setores em 2005 e a tracejada em 2050. Alguns dos setores aparecem aqui com pequena participação porque a produção de muitos não é voltada para o consumo das famílias, tendo outros destinos, como governo e exportações (como os setores educação pública e saúde pública, por exemplo, que registram produção, no caso deste estudo, apenas para o consumo indireto). De forma geral, verificou-se que a estrutura produtiva, mesmo com a expansão diferenciada no consumo entre os setores, não deve se alterar expressivamente, sendo que a distribuição da produção deve continuar basicamente a mesma.

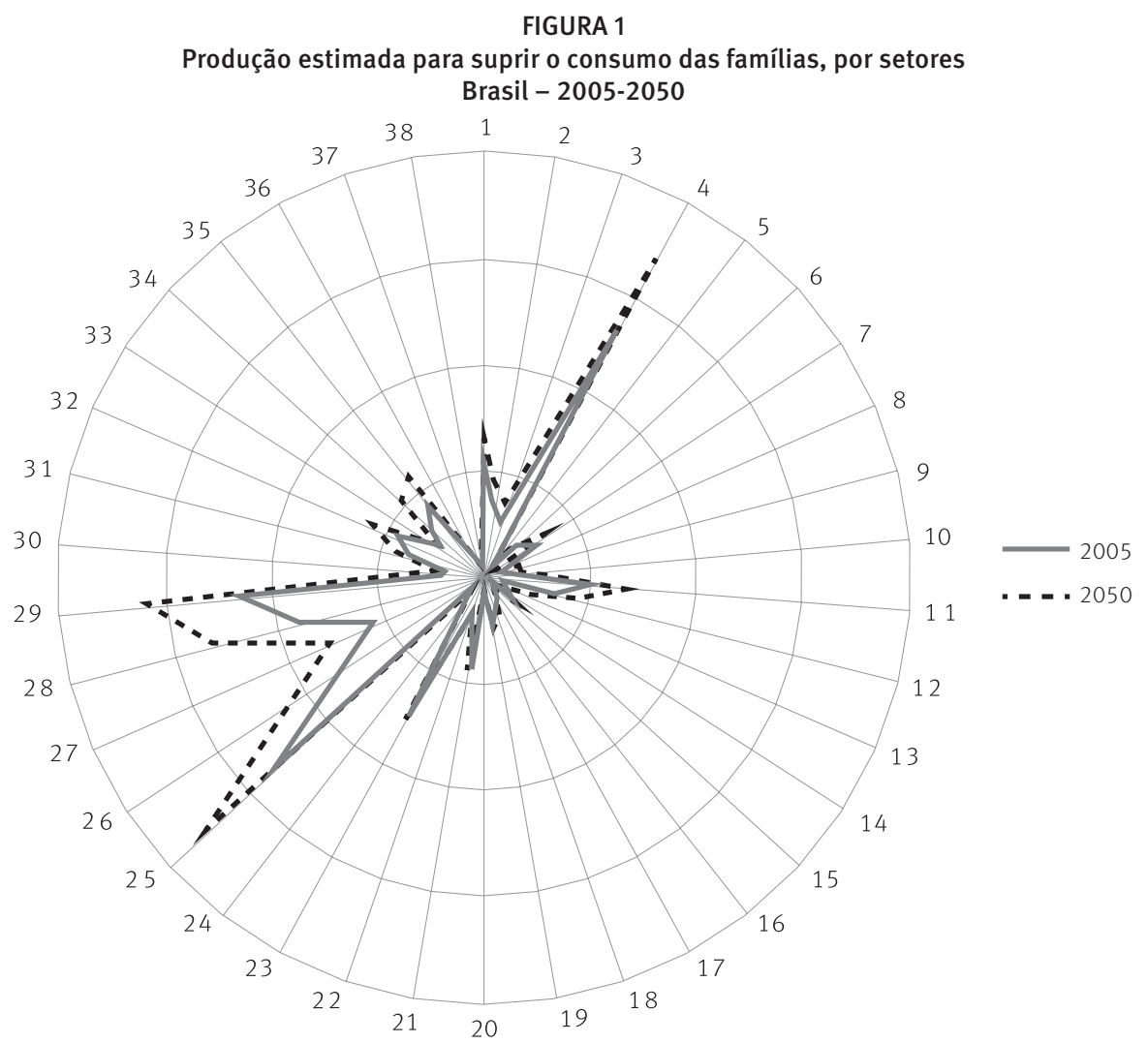

Fonte: IBGE. Pesquisa Nacional por Amostra de Domicílios 2005; Projeção da população do Brasil por sexo e idade para o período 1980-2050: revisão 2008; Matriz de insumo-produto Brasil 2005; Pesquisa de Orçamentos Familiares 2008-2009. Nota: Os dados para elaboração dessa Figura correspondem àqueles apresentados nas colunas 1 e 5 da Tabela 4.

Dados os estágios de envelhecimento populacional mais avançados observados em Portugal e na Escócia, Albuquerque e Lopes (2009) e Dewhurst (2006) puderam verificar um decréscimo no produto de vários setores e não apenas um crescimento menor, como no Brasil. Apesar disso, as tendências observadas entre estes países e o Brasil são as mesmas na maior parte dos setores. 


\section{Considerações finais}

O envelhecimento da população brasileira é fenômeno visível em razão do aumento da participação dos idosos na população total desde o final do século XX, quando as taxas de fecundidade passaram a apresentar quedas sucessivas e substanciais, revelando ser este um processo permanente, com diversas consequências, inclusive econômicas.

Dadas as diferenças entre a população idosa e a não idosa, tais como preferências e necessidades, renda, preço dos bens e serviços consumidos, taxa de juros (que é diferenciada para aposentados), renda esperada e sua riqueza, tem-se que o consumo das famílias idosas e não idosas difere substancialmente para diversos produtos, enquanto para outros não se observe diferença considerável.

Assim, o consumo verificado pela aplicação das proporções de consumo da POF 20082009 na matriz insumo-produto de 2005 revelou que a maior parte dos produtos mais consumidos pelas famílias idosas também é a mais demandada pelas não idosas, apesar de apresentarem diferentes participações em seus orçamentos, destacando-se intermediação financeira e seguros (40) e saúde mercantil (46). Já produtos relacionados ao bem-estar do idoso ou à sua saúde apareceram entre os maiores gastos das famílias idosas relativamente às não idosas, enquanto outros produtos, tais como a educação, não estavam entre os de maior consumo para as famílias idosas, mas apareciam para as não idosas.

Os resultados da produção estimada para satisfazer o consumo das famílias mostraram não haver trocas de posições entre os setores com maior produção, embora tenham sido observadas taxas diferentes de crescimento entre os setores. Estes resultados são condizentes com os apontados pelo World Economic and Social Survey (2007), que sugere que mudanças na composição da demanda devam ocorrer de forma lenta ao longo do tempo.

Os diferentes padrões de consumo verificados entre famílias idosas e não idosas devem impactar diferentemente os setores produtivos da economia brasileira, cabendo à iniciativa privada adaptar-se a estas mudanças, com o desenvolvimento de produtos para o público idoso, por exemplo. Assim, também o poder público deve ficar atento para suprir estes setores, com elevado crescimento, com a infraestrutura necessária e profissionais capacitados, inclusive porque muitos destes empregados tendem, cada vez mais, a fazer parte do grupo etário idoso, dado o aumento da participação destes no mercado de trabalho.

Ao governo cabe, também, acompanhar estas modificações na estrutura etária, para que o país possa aproveitar a elevação do potencial de crescimento que se abre com o processo de envelhecimento da população. Deve-se, portanto, ficar alerta com o já elevado custo das transferências públicas ao grupo idoso, e com o devido direcionamento do esperado aumento da poupança para investimentos produtivos.

Por fim, dada a natureza estática da metodologia utilizada, os resultados obtidos, enquanto importantes indicadores para a tomada de decisões nas esferas pública e privada, devem ser tomados de forma qualitativa. 
Para estudos futuros sugere-se analisar as mudanças na composição da população, na estrutura familiar e no padrão de consumo dentro de cada grupo etário, ao longo do tempo. Dessa forma, seria possível verificar se o padrão de consumo tende a se alterar com o passar dos anos ou não, como no estudo de DellaVigna e Pollet (2007) para os Estados Unidos, e como isto afeta a estrutura produtiva da economia.

\section{Referências}

ALBUQUERQUE, P. C.; LOPES, J. C. Economic impacts of aging in Portugal: an interindustry approach. In: INTERNATIONAL INPUT-OUTPUT CONFERENCE, 17th. São Paulo, 2009.

ALMEIDA, A. N. Determinantes do consumo de famílias com idosos e sem idosos com base na Pesquisa de Orçamentos Familiares 1995/96. Piracicaba, 2002. 94p. Dissertação (Mestrado). Escola Superior de Agricultura Luiz de Queiroz, Universidade de São Paulo, Piracicaba, 2002.

BALLSTAEDT, A. L. M. P. Comportamento e estilo de vida da população idosa e seu poder de consumo. In: ENCUENTRO LATINOAMERICANO DE DISEÑO, 2. Anales... Buenos Aires, 2007. Disponível em: «http://fido. palermo.edu/servicios_dyc/encuentro2007/02_auspicios_publicaciones/actas_diseno/articulos_pdf/ A004.pdf〉. Acesso em: 24 maio 2011.

BANCO MUNDIAL. Envelhecendo em um Brasil mais velho. Banco Mundial/LAC, Brasil, 2011.

BRITO, F. A transição demográfica no Brasil: as possibilidades e os desafios para a economia e a sociedade. Minas Gerais: Cedeplar/UFMG, 2007 (Textos para a discussão, 318).

CAMARANO, A. A.; PASINATO, M. T. Introdução. In: CAMARANO, A. A. (Org.). Os novos idosos brasileiros: muito além dos 60? Rio de Janeiro: Ipea, 2004.

CARVALHO, J. A. M.; GARCIA, R. A. O envelhecimento da população brasileira: um enfoque demográfico. Cadernos de Saúde Pública, v. 19, n. 3, p. 725-733, 2003. Disponível em: 〈http://www. scielosp.org/pdf/csp/v19n3/15876.pdf> Acesso em: 10 maio 2011.

DEWHURST, J. H. L. Estimating the effect of projected household composition change on production in Scotland. University of Dundee, Department of Economic Studies, 2006 (Working paper, n. 186). Disponivel em: 〈http://www.dundee.ac.uk/econman/discussion/DDPE_186.pdf〉 Acesso em: 10 jan. 2011.

DELLAVIGNA, S.; POLLET, J. M. Demographics and industry returns. American Economic Review, v. 97, p. 1167-1702, 2007. Disponível em: 〈http://elsa.berkeley.edu/ sdellavi/wp/demogrAERFinal.pdf〉. Acesso em: 20 abr. 2012.

DORNBUSCH, R.; FISCHER, S. Macroeconomia. 5 ed. São Paulo: Makron Books, 1991.

GUILHOTO, J. J. M. Análise insumo-produto: teoria e fundamentos. São Paulo: USP, FEA, Departamento de Economia, 2006.

GUIMARÃES, J. R. S. Envelhecimento populacional e oportunidade de negócios: o potencial de mercado da população idosa. In: ENCONTRO NACIONAL DE ESTUDOS POPULACIONAIS, 15. Anais... Campinas: Abep, 2006. Disponivel em: 〈http://www.abep.nepo.unicamp.br/encontro2006/docspdf/ ABEP2006_540.pdf>Acesso em: 12 maio 2011.

HAGEMANN, R. P.; NICOLETTI, G. Population ageing: economic effects and some policy implications for financing public pensions. OECD Economic Studies, n. 12, p. 51-96 [Spring 1989]. Disponível em: 〈http:www.oecd.org/dataoecd/17/18/35379092.pdf〉. Acesso em: 15 jul. 2011.

IBGE - Instituto Brasileiro de Geografia e Estatística. Pesquisa Nacional por Amostra de Domicílios 2005. Rio de Janeiro, 2005. CD-ROM. 
Projeção da população do Brasil por sexo e idade para o período 1980-2050: revisão 2008. Rio de Janeiro, 2008a. Disponível em: 〈http://www.ibge.gov.br/home/estatistica/populacao/ projecao_da_populacao/2008/projecao.pdf〉. Acesso em: 09 jun. 2011.

Matriz de insumo-produto Brasil 2005. Rio de Janeiro, 2008b. Disponível em: 〈ftp://ftp. ibge.gov.br/Matriz_insumo-produto/MIPN55/2005.zip〉. Acesso em: 15 fev. 2010.

Pesquisa Nacional por Amostra de Domicílios 2009. Rio de Janeiro, 2009a. CD-ROM.

Pesquisa de Orçamentos Familiares 2008-2009. Rio de Janeiro, 2009b. CD-ROM.

Censo Demográfico 2010: resultados preliminares da amostra. Rio de Janeiro, 2011. Disponivel em: <ftp://ftp.ibge.gov.br/Censos/Censo_Demografico_2010/Resultados_Preliminares_ Amostra/tabelas_de_resultados.zip >. Acesso em: 10 nov. 2011.

LÜHRMANN, M. Population aging and the demand for goods \& services. Mannheim Research Institute for the Economics of Aging (MEA), University of Mannheim, 2005. (MEA discussion paper series 05095). Disponivel em: 〈http://www.mea.uni-mannheim.de/uploads/user_mea_discussionpapers/ gtyzs5eximf4u8v9_95-2005.pdf〉. Acesso em: 20 fev. 2011.

MILLER, R. E.; BLAIR, P. D. Input-output analysis: foundations and extensions. New York: Cambridge University Press, 2009.

MOREIRA, M. M. Envelhecimento da população brasileira: aspectos gerais. In: WONG, L. R. (Org.). 0 envelhecimento da população brasileira e o aumento da longevidade: subsídios para políticas orientadas ao bem-estar do idoso. Belo Horizonte: Cedeplar/UFMG, Abep, 2001, p. 25-56. Disponível em: 〈http://www.abep.nepo.unicamp.br/docs/outraspub/envelhecimento/Env_p25a56.pdf〉. Acesso em: 18 abr. 2011.

NERI, M. et al. Inflação e os idosos brasileiros. In: CAMARANO, A. A. (Org.). Os novos idosos brasileiros: muito além dos 60? Rio de Janeiro: Ipea, 2004.

QUEIROZ, B. L.; TURRA, C. M. Window of opportunity: socioeconomic consequences of demographic changes in Brazil. Washington, DC: NTA, 2010. Disponivel em: 〈http://www.ntaccounts.org/doc/ repository/QT2010.pdf). Acesso em: 18 abr. 2012.

RICHARDSON, H. W. Insumo-produto e economia regional. Rio de Janeiro: Zahar, 1978.

TURRA, C. M. et al. Idiosyncrasies of intergenerational transfers in Brazil. In: LEE, R.; MASON, A. (Orgs.). Population aging and the generational economy: a global perspective. Edward Elgar Publishing, 2011, p. 394-407.

WORLD ECONOMIC AND SOCIAL SURVEY 2007. Development in an ageing world. New York: United Nations Publication, 2007.

ZANON, R. R. Envelhecimento populacional e mudanças no padrão de consumo: impactos na estrutura produtiva do Brasil. 2012. 77 f. Dissertação (Mestrado em Economia Regional) - Centro de Estudos Sociais Aplicados, Universidade Estadual de Londrina, Londrina-PR, 2012.

\section{Autores}

Rodrigo Rafael Zanon é mestre em Economia Regional pela Universidade Estadual de Londrina.

Antonio Carlos Moretto é doutor em Economia Aplicada pela Escola Superior de Agricultura "Luiz de Queiroz" - Esalq/Universidade de São Paulo - USP. Professor associado do Departamento de Economia da Universidade Estadual de Londrina.

Rossana Lott Rodrigues é doutora em Economia Aplicada pela Escola Superior de Agricultura "Luiz de Queiroz" - Esalq/Universidade de São Paulo - USP. Professora associada do Departamento de Economia da Universidade Estadual de Londrina. 


\section{Abstract \\ Aging of Population and Changes in Consumption Patterns: impacts on the production structure in Brazil}

The main objective of this paper is to analyze how the aging of the population could affect the Brazilian production structure, given the expected changes in consumption patterns of the population between 2005 and 2050. To achieve this objective an input-output analysis was used together with information from the 2008-2009 Consumer Expenditure Survey (POF), the 2005 National Household Sample Survey (PNAD) and a projection of Brazil's population by sex and age between 1980 and 2050. The most important results were that: a) the products most heavily consumed in elderly households were Financial Intermediation and Insurance, the Health Market, Domestic Services, and Pharmaceutical Products, whereas in non-elderly families more was spent on Private Education, Clothing, Footwear and Leather Products, Passenger Transport, and Lodging and Food; b) when the production required to satisfy household consumption in the years analyzed was compared, it was found that the sectors with the highest growth rates are likely to be those responsible for products with higher consumption among elderly families, especially the areas of Pharmaceutical Products, Health Care, Financial Intermediation and Insurance, Other Services, Medical and Hospital Devices and Instruments, Measurement and Optical, and Real Estate and Rental Services. In contrast, sectors with lower growth in production will probably include Private Education, Clothing, Footwear and Leather Products, Lodgings and Food, Tobacco Products, Motor Vehicles, Parts and Equipment, and, finally, c) despite the differences in the growth of the sectors, the Brazilian production structure is not likely to change greatly as the result of changes in the consumption caused by the aging of the population.

Keywords: Aging. Consumption. Production structure. Input-output.

\section{Resumen}

Envejecimiento Poblacional y Cambios en el Estándar de Consumo: impactos en la estructura productiva de Brasil

Este trabajo tuvo como principal objetivo analizar cómo el envejecimiento poblacional puede afectar la estructura productiva brasileña en función de los cambios previstos en el estándar de consumo de la población entre los años 2005- 2050. Para alcanzar dicho objetivo se utilizó el análisis insumoproducto en conjunto con informaciones de la Pesquisa de Orçamentos Familiares (POF) (Investigación de Presupuestos Familiares) de 2008-2009, de la Pesquisa Nacional por Amostra de Domicílios (PNAD) (Investigación Nacional por Muestreo de Domicilios) de 2005 y de la proyección de la población de Brasil por sexo y edad para el periodo de 1980-2050. Entre los resultados se destacan los siguientes: a) los productos con mayor consumo en favor de las familias mayores fueron Intermediación Financiera y Seguros, Salud Mercantil, Servicios Domésticos y Productos Farmacéuticos, mientras que para el caso de las familias non mayores los destaques fueron Educación Mercantil, Vestimenta, Calzados y Productos de Cuero, Transporte de pasajeros y Servicios de alojamiento y alimentación; b) cuando se compara la producción necesaria para satisfacer el consumo de las familias en los años analizados, se verifica que los sectores que presentan mayor crecimiento deben ser aquellos responsables por los productos más consumidos por las familias mayores, con destaque para los sectores Productos Farmacéuticos, Salud Mercantil, Intermediación Financiera y Seguros, Otros Servicios, Aparatos/ Instrumentos Médico-Hospitalario, Medida y Óptico, y Servicios Inmobiliarios y Alquiler, al paso que los sectores que presentan menor crecimiento de su producción deben ser Educación Mercantil, 
Vestimenta, Calzados y Productos de Cuero, Servicios de Alojamiento y Alimentación, Productos de Tabaco, Vehículos Automotores, Repuestos y Equipos; c) por fin, a pesar de tales diferencias observadas en el crecimiento de los sectores, la estructura productiva brasileña debe alterarse poco debido a los cambios en el consumo ocasionados por el envejecimiento poblacional.

Palabras clave: Envejecimiento poblacional. Consumo. Estructura productiva. Insumo-Producto.

Recebido para publicação em 01/02/2012

Aceito para publicação em 14/05/2012 
